\title{
Improving health systems through innovation in population health and health services
} research

\author{
Danielle M Campbella,b,c, Beth Stickneyª,b, Andrew J Milatta,b and Sarah \\ Thackwaya,b \\ ${ }^{a}$ Centre for Epidemiology and Evidence, NSW Ministry of Health, Sydney, Australia \\ b Guest Editor, Public Health Research \& Practice, Issue 3, 2018 \\ c Corresponding author: Danielle.Campbell@health.nsw.gov.au
}

\section{Article history}

Publication date: September 2018

Citation: Campbell DM, Stickney B, Milat AJ, Thackway S. Improving health systems through innovation in population health and health services research. Public Health Res Pract. 2018;28(3):e2831814. https://doi. org/10.17061/phrp2831814
The pace of change in healthcare has never been so great, disrupting health systems in a manner that would have been unimaginable just a few decades ago. Rapidly evolving information and communication technologies have the capacity to transform how we work, enabling us to deliver programs and provide care in innovative ways. ${ }^{1}$ However, many promising technological innovations in health are not adopted, are abandoned, or fail to scale up or spread across organisations or systems. ${ }^{2}$ The vexed issue of how to successfully implement technological innovation in health projects is highlighted in this issue by Greenhalgh ${ }^{3}$, who provides direction for policy makers and planners to address multiple complexities when implementing technological change.

Yet not all health system innovation is technological in nature. Innovation can occur in many different ways, including through the implementation of new or altered services, processes, systems, policies or business models. ${ }^{4}$ Such innovations may relate to how healthcare or programs are organised and provided, the way research is funded and conducted, or approaches to encouraging better use of research evidence. During the past decade there has been an explosion of interest in encouraging research use to make an optimal impact on policy. The paper by Campbell and Moore ${ }^{5}$ in this issue presents findings from a rapid review of work in this area. The review highlights the lack of strong evidence of effectiveness in this field, but does point to some promising approaches such as involving policy makers in research teams and organisation-wide capability development.

Recent policy initiatives at the Australian national level acknowledge the need for new ways of working to support health and medical innovation through research. The Medical Research Future Fund (MRFF), for example, was established in 2015 as a vehicle for strategic investment in health and medical research to complement existing research funding. The objectives of the MRFF, as set out in the Australian Medical Research and Innovation Strategy 2016-2021, include a commitment to "drive collaboration and innovation across the research pipeline and healthcare system". 6 Reflections on the benefits of and challenges to a collaborative approach to research are presented in the paper by Slaytor and colleagues. ${ }^{7}$ This paper describes experiences from the first 5 years of The Australian Prevention 
Partnership Centre, a new way of working that brings together prevention academics, policy makers and practitioners from across the country.

At the state level, the importance of continuing to pursue cutting-edge health and medical research to accelerate innovation is also recognised. The New South Wales (NSW) State Health Plan includes a strategic focus on supporting and harnessing research and innovation to create healthier communities and deliver better patient care, noting the need to ensure that effective innovations are successfully scaled up, rolled out and embedded system-wide. ${ }^{8}$ The paper by Green and colleagues ${ }^{9}$ discusses an excellent example of using an information management system to measure the reach and adoption of childhood obesity prevention programs delivered at scale in more than 6500 early childhood services and primary schools across NSW.

The strategic focus on research to improve health is reinforced by the NSW Health Population Health Research Strategy 2018-2022, which supports continued investment in population health research in areas of existing research strength and in areas of emergence and innovation. ${ }^{10}$ The strategy encourages a focus on policy-relevant research, and particularly intervention research, to directly inform practice. This issue includes three papers that illustrate the breadth of investment by NSW Health in priority-driven population health research. Our 'In practice' paper ${ }^{11}$ describes the Prevention Research Support Program (PRSP), a funding scheme that provides infrastructure support to NSW research groups conducting highquality, policy-relevant prevention research. Gordon and colleagues $^{12}$ describe the BBV \& STI Research Intervention and Strategic Evaluation (BRISE) program, established to deliver priority-driven research to support the NSW Health response to blood-borne viruses (BBV) and sexually transmissible infections (STI). Auld and colleagues $^{13}$ present an overview of and insights from initial rounds of the Translational Research Grants Scheme (TRGS), a novel approach to funding applied research projects that have potential to drive practice improvements in NSW health services. Funded projects are led by NSW Health practitioners, focus on state or local priority issues, and require a commitment from chief executives of the host organisations to implement practice change based on the research findings.

The themed articles in this issue elucidate advances in health technologies and initiatives that support the generation and use of research evidence to improve health policy and practice. They also point to the need for further work in managing the complexity of technological innovation, supporting coproduction of research by researchers and practitioners, and evaluating strategies for encouraging use of research evidence. Ongoing work across the spectrum of NSW Health's research investment portfolio will go some way to addressing these future challenges. ${ }^{14}$

We hope our readers enjoy these themed papers and all the articles in this edition of Public Health Research \& Practice.

\section{Peer review and provenance}

Internally peer reviewed, commissioned.

\section{Competing interests}

None declared.

\section{Author contributions}

$\mathrm{DC}, \mathrm{BS}$ and $\mathrm{AM}$ contributed to the conception and structure of the editorial, and DC drafted the editorial content. DC, BS, AM and ST reviewed and approved the editorial.

\section{References}

1. Westbrook JI, Braithwaite J. Will information and communication technology disrupt the health system and deliver on its promise? Med J Aust. 2010;193:399-400.

2. Greenhalgh T, Wherton J, Papoutsi C, Lynch J, Hughes G, A'Court C, et al. Beyond adoption: a new framework for theorizing and evaluating nonadoption, abandonment, and challenges to the scale-up, spread, and sustainability of health and care technologies. J Med Internet Res. 2017;19(11):e367.

3. Greenhalgh T. How to improve success of technology projects in health and social care. Public Health Res Pract. 2018;28(3):e2831815.

4. AHRQ Health Care Innovations Exchange. Rockville: Agency for Healthcare Research and Quality; 2016. About the AHRQ Health Care Innovations Exchange; 2014 [cited 2018 Aug 22]; [about 3 screens]. Available from: innovations.ahrq.gov/about-us

5. Campbell DM, Moore G. Increasing the use of research in population health policies and programs: a rapid review. Public Health Res Pract. 2018;28(3):e2831816.

6. Australian Medical Research Advisory Board. Australian Medical Research and Innovation Strategy 2016-2021. Canberra: Australian Government; 2016 [cited 2018 Aug 15]. Available from: beta.health.gov.au/resources/ publications/australian-medical-research-and-innovationstrategy-2016-2021

7. Slaytor E, Wilson A, Rowbotham S, Signy H, Burgess A, Wutzke S. Partnering to prevent chronic disease: reflections and achievements from The Australian Prevention Partnership Centre. Public Health Res Pract. 2018;28(3):e2831821.

8. NSW Ministry of Health. NSW State Health Plan: towards 2021. Sydney: NSW Ministry of Health; 2014 [cited 2018 Jul 26]. Available from: www.health.nsw.gov.au/ statehealthplan/Publications/NSW-state-health-plantowards-2021.pdf 
9. Green AM, Innes-Hughes C, Rissel C, Mitchell J, Milat AJ, Williams $\mathrm{M}$, et al. Co-design of the Population Health Information Management System to measure reach and practice change of childhood obesity programs. Public Health Res Pract. 2018;28(3):e2831822.

10. Centre for Epidemiology and Evidence. Population Health Research Strategy 2018-2022. Population and Public Health Division. Sydney: NSW Ministry of Health; 2018 [cited 2018 Jul 26]. Available from: www.health.nsw.gov. au/research/Publications/research-strategy-2018-2022.pdf

11. Stickney B, Campbell DM, Milat AJ, Thackway S. The Prevention Research Support Program: supporting innovation in research, translation and capability building. Public Health Res Pract. 2018;28(3):e2831819.
12. Gordon T, Power C, Duck T, Schmidt H-MA, Holden J. A priority-driven, policy-relevant research program to support a response to blood-borne viruses and sexually transmissible infections in NSW, Australia. Public Health Res Pract. 2018;28(3):e2831820.

13. Auld R, Loppacher T, Rose S, Milat AJ, Penna A. Translational Research Grants Scheme (TRGS): a new approach to strengthening health system research capacity. Public Health Res Pract. 2018;28(3):e2831818.

14. Thackway S, Campbell D, Loppacher T. A longterm, strategic approach to evidence generation and knowledge translation in NSW, Australia. Public Health Res Pract. 2017;27(1):e2711702.

\section{Copyright: (c) (i) (2)}

(C) 2018 Campbell et al. This article is licensed under the Creative Commons Attribution-NonCommercial-ShareAlike 4.0 International Licence, which allows others to redistribute, adapt and share this work non-commercially provided they attribute the work and any adapted version of it is distributed under the same Creative Commons licence terms. See: www.creativecommons.org/licenses/by-nc-sa/4.0/ 